\title{
O mal-estar da Gerechtigkeit
}

Luis S. Krausz ${ }^{1}$

\begin{abstract}
Der Fall Maurizius by Jakob Wassermann was first published in 1928. It is set partly in 1908 Germany and partly during the Weimar Republic. In this work, Wassermann criticizes German pragmatism by depicting the State bureaucracy as the absolute power over citizens, even after the Imperial Era. Disgusted with the mismanagement of the justice system and with the perverse character of those in charge, the author renders German pragmatism as nonadherence to the moral values supposedly justifying the State apparatus - in particular, as a breach of the Gerechtigkeit principle. The harmless innocence of the adolescent Etzel von Andergast, the only child of a well-known prosecutor, highlights this violation of justice. At the same time, Waremme is a sinister character whose Jewish parents fled from Prussian-occupied Poland. He breaks with his ancestors' moral values and is eager to play a key role in the German Nationalistic movement. However, he feels frustrated with his project of cultural assimilation and is pushed towards the outskirts of a bewildered society. The crisis of values and transgression of justice become the emblems of Wassermann's generation.
\end{abstract}

Keywords: German literature; Jewish literature; Weimar Republic; crisis of values; assimilation.

Resumo: Em Der Fall Maurizius, romance de Jakob Wassermann de 1928, parcialmente ambientado em 1908, à época da República de Weimar, o autor critica o pragmatismo alemão, apoiado numa burocracia de estado que, mesmo depois do fim do Império, continua a exercer o poder de maneira absoluta. Wassermann revolta-se contra a má administração da justiça, e contra o caráter perverso daqueles que, tendo se apoderado do aparelho estatal, arrogam a si mesmos o papel de representantes dos melhores princípios do humanismo alemão. O pragmatismo, assim, apresenta-se como a falsificação daqueles valores que supostamente o legitimariam - notadamente, do princípio de Justiça, Gerechtigkeit. A inocência de um adolescente, Etzel von Andergast, filho de um grande promotor, é o que traz à luz este estado de adulteração. Ao mesmo tempo, a figura de Waremme, descendente de judeus provenientes de regiões da Polônia ocupadas pela Prússia desde 1772, é uma figura sinistra, que rompeu com o legado ético de seus antepassados, pretendendo exercer um papel de destaque no movimento nacionalista alemão, para frustrar-se e ocupar posição marginal numa sociedade repleta de desencaminhados e perplexos. Desta forma o autor representa as aporias de uma geração que sente na pele esse exílio da justiça e a crise generalizada de valores.

Palavras-chave: Literatura alemã; literatura judaica; República de Weimar; crise de valores; assimilação.

\footnotetext{
${ }^{1}$ Doutor em Literatura e Cultura Judaica pela Universidade de São Paulo, pesquisador com apoio da FAPESP junto à área de Língua Hebraica, Literatura e Cultura Judaicas da FFLCH/USP.

E-mail: $\underline{\text { krausz@uol.com.br }}$
} 


\section{A natureza do estranhamento}

Jakob Wassermann (1873-1934) nasceu de uma família judia assimilada da pequena burguesia, na Francônia ${ }^{2}$. Desde cedo percebeu, em sua vida particular e no ambiente em que foi educado, a cisão crescente entre as raízes judaicas, das quais sua família se desvinculara a ponto de reduzir seu judaísmo a uma questão meramente confessional, e o ambiente secular em que vivia, marcado pelo preconceito anti-semita. Serviu ao exército imperial, onde foi cruelmente discriminado por causa de sua ascendência e de sua constituição frágil, e cedo tornou-se um cético com relação ao processo de aculturação e germanização dos judeus da Alemanha que, no seu entender, dava-se ao custo do sacrifício de toda a autenticidade de um grupo que imolava sua personalidade, sua tradição espiritual e sua essência no altar-mor da conquista de posições no interior da sociedade alemã. Assim, ao descrever seus contemporâneos, judeus alemães em processo de assimilação, ou judeus orientais em processo de germanização, ele escreveria, em 1924, no capítulo intitulado "Der Jude als Orientale” (“O Judeu como Oriental”) de sua autobiografia (WASSERMANN 1984: 24):

De um só golpe deseja-se tirar de si mesmo tudo o que se foi para sentir-se no presente. O resultado é embriaguez, desorientação, cisão (...). Por excesso de ambição, as pessoas se tornam viciadas. O prazer da vitória as leva a se esquecerem do fato de que, apesar dos direitos conquistados, apenas são toleradas. Tudo o que os judeus têm de excelente degradou-se em vícios e estes vícios, nos judeus, possuem algo de estranhamente penetrante: o judeu autêntico é orgulhoso e cheio de pudor; eles são servis e desavergonhados. Neles a inteligência se transforma em esperteza, o julgamento em falta de respeito. São fracos que se fazem passar por fortes. ${ }^{3}$

\footnotetext{
2 cf. WASSERmAnN, Jakob Mein Weg als Deutscher und Jude, Munique, Deutscher Taschenbuch Verlag, 1994, p. 37: Na roupa, na fala e nas formas de vida a assimilação estava totalmente concluída. A escola que eu freqüentava era estatal e aberta. Vivíamos entre cristãos, relacionávamo-nos com cristãos, e para os judeus modernizados, dentre os quais meu pai se incluía, uma comunidade judaica existia apenas no sentido do culto e da tradição. Este recuava, ante o poderoso e sedutor ser moderno, cada vez mais para a esfera reservada das congregações, em grupos secretos, distantes, frenéticos; aquela tornava-se lenda, e por fim apenas palavra e forma vazia. (In Kleidung, Sprache und Lebensform war die Anpassung durchaus vollzogen. Die Schule, die ich besuchte, war staatlich und öffentlich. Man wohnte unter Christen, verkehrte mit Christen, und für die fortgeschrittenen Juden, zu denen mein Vater sich zählte, gab es eine jüdische Gemeinde nur im Sinn des Kultus und der Tradition; jener wich vor dem verführerischen und mächtigen modernen Wesen mehr und mehr ins Konventikelhafte zurück, in heimliche, abgekehrte, frenetische Gruppen; diese wurde Sage, schliesslich nur Wort und leere Hülse.)

${ }^{3}$ „Man will in einem Atemzug alles Gewesene abschütteln und sich mit Gegenwart fühlen. Die Folge ist Rausch, Zerfahrenheit, Zerrissenheit (...). Man wird durch Übereifer lästig. Die Siegerfreude lässt vergessen, dass man trotz der errungenen Rechte nur geduldet wird. (...)Alle Vorzüge des Juden sind zu
} 
Mais adiante lemos, no mesmo livro (WASSERMANN 1984: 30):

Nele tudo se torna gesto, calor excessivo, tudo se torna mania. É como se ele tivesse sido privado da noção de seu próprio ser e em decorrência disto ele precisa arrancar cada sucesso, cada efeito, cada desafio de sua personalidade isolada, e assim não possui nada além desta própria personalidade, da qual ele é vítima e escravo (...).

Nós os conhecemos, meu caro amigo, nós os conhecemos e sofremos por causa deles, estes milhares de assim chamados judeus modernos, que minam todos os fundamentos porque eles mesmos não têm fundamentos; que hoje jogam fora 0 que conquistaram ontem, que hoje emporcalham o que ontem amavam... Eles só se entregam às coisas nas quais podem se perder, e só admiram onde se sentem desprezados. No fundo de seus corações eles crêem apenas no estranho, no outro, no ser diferente. ${ }^{4}$

Para Wassermann, o judeu "modernizado" é o homem que paira suspenso entre dois mundos, alguém que não sabe ao certo quem é, que não se parece com ninguém e que com ninguém parece capaz de relacionar-se com naturalidade. Privado de sua natureza, que o autor implicitamente atribui a um universo ostjüdisch, ou judaicooriental - que, no entanto, à maneira de Kafka e Döblin, Wassermann não chegou a conhecer realmente - esse judeu modernizado vive cercado por uma aura de exotismo e diferença, mas já não é mais capaz de encontrar sua identidade, e assim parece estar sob o poder de uma espécie de maldição, que o acompanha em toda a parte.

A angústia desse judeu modernizado concebido por Wassermann está presente, de maneira exacerbada também em sua ficção e o personagem que representa de forma mais eloqüente essa condição em sua obra é o misterioso Gregor Waremme, aliás, Georg Warschauer, personagem principal do romance Der Fall Maurizius, ${ }^{5}$ publicado pela primeira vez em 1928. A preocupação com a alienação, com a angústia da nãopertinência, é já o assunto central de seu Kaspar Hauser, romance de 1907, centrado em torno de um personagem real, que perdeu todo o contato com suas origens, desesperado

Lastern geworden und diese Laster haben bei ihm etwas seltsam Penetrantes: der echte Jude ist stolz und schamhaft, sie sind knechtisch und schamlos. In ihnen wird Scharfsinn zur Klügelei, Urteil zu Respektlosigkeit. Es sind Schwächlinge die sich stark stellen."

${ }^{4}$ „,Alles wird Gebärde an ihm, alles Überhitzung, alles Manie. Ihm ist sozusagen die Idee seines Daseins geraubt, infolgedessen muss er jeden Erfolg, jede Wirkung, jede Förderung seiner eigenen isolierten Persönlichkeit abzwingen, und so besitzt er auch nichtes weiter als eben diese Persönlichkeit, deren Sklave und Opfer er ist (...).",

Wir kennen sie ja, lieber Freund, wir kennen sie und wir leiden an ihnen, diesen tausenden sogenannten modernen Juden, die alle Fundamente benagen, weil sie selbst ohne Fundament sind; die heute verwerfen, was sie gestern erobert, heute besudeln, was sie gestern geliebt.... Sie geben sich nur hin, wo sie sich verlieren können, und bewundern nur dort, wo sie sich verstossen fühlen. Im Grunde ihres Herzens glauben sie bloss an das Fremde, das Andere, das Anderssein.”

${ }^{5}$ Traduzido para o português sob o titulo de O Processo Maurizius, São Paulo, Abril Cultural, 1975 
em sua solidão, sequioso de um encontro com sua história verdadeira tanto quanto de laços autênticos com o mundo que o cerca - e incapaz de encontrar satisfação para qualquer destes seus anseios. Waremme, tanto quanto Kaspar Hauser, é um personagem atormentado pela sensação de estranhamento e por uma busca pela própria identidade que chega às raias do desespero, e que talvez possa ser vista como uma ressonância da tenacidade das próprias angústias de Wassermann, expressas em Mein Weg als Deutscher und Jude. Ao mesmo tempo, Waremme é um emblema do desenraizamento na modernidade de uma forma mais ampla, de maneira que sua condição de judeu alienado de suas origens e de sua tradição também pode ser vista como aplicável à sociedade alemã do pós-guerra de um modo geral. Seja como for, a busca desesperada por um vínculo com uma Heimat, com um lar físico e espiritual, é o traço de caráter que marca de maneira decisiva Gregor Waremme, esse personagem aberrante de Der Fall Maurizius.

\section{Gerechtigkeit: um incômodo refúgio}

Além de tratar da questão da alienação, por meio desse personagem, Der Fall Maurizius é, tanto quanto o Kaspar Hauser, um romance a respeito da Gerechtigkeit, esse conceito de justiça e de retidão moral que é, para o idealismo alemão, o mesmo que a noção de Diké significa no universo na filosofia platônica. A Gerechtigkeit e sua perversão por uma sociedade e por um estado construídos sobre as bases da violência e da injustiça são as forças opostas cuja interação define os desdobramentos dessa narrativa. O romance, que tem dois tempos ficcionais distintos - 1908 e 1926 - trata da condenação indevida de Leonhart Maurizius por um assassinato que, na realidade, não cometeu, depois de um processo muito comentado em seu tempo, em que um promotor ambicioso, Wolf von Andergast, acaba por conseguir levá-lo ao cárcere. O responsável pela aplicação da justiça, assim, transforma-se em algoz, movido por sua ambição desmedida. Dezoito anos mais tarde, o filho de Andergast, Etzel, de 16 anos, descobre o papel exercido pelo pai, que arroga a si mesmo o papel de baluarte da justiça e da autoridade. Convencido de que houve uma perversão da justiça, parte para uma investigação particular do caso, buscando o pai de Maurizius, que há 18 anos luta com todas as suas forças para conseguir a libertação do filho, bem como Gregor Waremme, que conhece a verdade sobre o caso - um filho de judeus das províncias polonesas 
anexadas à Prússia em 1772, cuja promissora carreira política e intelectual na Alemanha foi abortada pela discriminação e pelo anti-semitismo.

Der Fall Maurizius, assim como Der Prozeß de Franz Kafka, publicado três anos antes, em 1925, é um romance que se volta contra a complexidade e a ineficiência das grandes burocracias judiciais, desvinculadas daquele princípio universal de justiça que está na base do idealismo alemão, isto é, um romance sobre a perversão da Gerechtigkeit. Ao mesmo tempo, na figura de Waremme, este descendente de Ostjuden, condensa-se toda a problemática da crise de identidade judaica na Alemanha. Waremme é um homem que vive entre duas culturas e entre dois mundos - a modernidade germânica e a tradição judaica - mas cuja monstruosidade é decorrência de seu abandono dos princípios éticos, substituídos por uma retórica que se baseia na sensualidade, à maneira do retórico grego Górgias - protagonista do diálogo platônico de mesmo nome, do qual Waremme não por acaso teria sido tradutor para o alemão. A perversão da ética e da justiça, portanto, perpassa a narrativa como um todo, e define os dois pólos que a delimitam: o autoritário e poderoso promotor Andergast, de um lado, e o ardiloso e desarraigado Waremme de outro. Se um encarna a rigidez autoritária dos burocratas de estado alemães, seu formalismo, e sua fixação pelas formas estabelecidas da lei, independentemente de qualquer outro tipo de consideração humana, o outro torna-se um emblema da desarticulação de todos os princípios e fundamentos da moralidade num indivíduo que tem na condição de estranho no mundo a definição de sua identidade.

Ao mesmo tempo, o estranhamento e a alienação de Etzel, o filho adolescente de Andergast, ante o rigor implacável de seu pai, e a descoberta, por ele, da injustiça que levou à condenação de Leonhart Maurizius, constitui o conflito central em torno do qual Wassermann constrói essa narrativa complexa, que se aprofunda nos paradoxos e nas aporias do homem moderno, e nas perplexidades da Alemanha do entre-guerras, desestabilizada pela perda de paradigmas tanto quanto pela humilhação sofrida ante seus inimigos na guerra de 1914-1918.

Andergast é essa figura sinistra e ao mesmo tempo aparentemente tão digna e tão segura de si, que representa, no romance, aquele mesmo traço de caráter presente em personagens como o Professor Quandt, do Kaspar Hauser: convicto de suas obrigações e de seus deveres para com a ordem constituída, ele encarna aquelas virtudes da obediência total, que são o fundamento de uma eficiência burocrática tão admirável quanto privada de humanidade, e cuja formação está inextricavelmente ligada ao 
despotismo esclarecido do século 19. Andergast é, sem saber, vítima da mesma Trägheit des Herzens (indolência do coração) que afeta aqueles que precipitam Kaspar Hauser em sua tragédia, e alguém que foi educado para transformar em orgulho sua capacidade de empatia, em arrogância seus sentimentos, em indiferença qualquer sentido de solidariedade, até mesmo com o próprio filho - cuja mãe foi expulsa de casa e proibida de qualquer tipo de contato com ele por ter tido um caso de amor extra-conjugal.

O implacável Andergast regulamenta de forma maquinal todos os horários e todas as atividades de seu filho, como de resto os funcionários oficiais e domésticos sob seu comando, e assim reflete o aspecto militarista de uma mentalidade em que a submissão à ordem se torna o valor supremo, ao mesmo tempo em que qualquer tipo de questionamento ao caráter absoluto dessa ordem é imediatamente visto como sumariamente condenável: o antigo absolutismo esclarecido do Imperador, que se estendia, por meio da lealdade inquestionável dos seus burocratas, a todas as esferas da vida de seus súditos, quer permanecer incólume depois do fim do Império e os burocratas de Estado do molde de Andergast, como heranças de uma outra era, fazem as vezes de longos tentáculos que pretendem penetrar nos espaços mais recônditos das vidas de cidadãos, como uma presença incômoda, permanente e inexorável, capaz de levá-los às raias da paranóia.

Um funcionalismo que arroga a si mesmo o papel de destino e de nêmesis de populações inteiras é o aspecto patológico que Wassermann identifica num Estado que não está construído sobre princípios humanos autênticos e verdadeiros, mas sobre o exercício quotidiano da violência legitimada pela forma da lei. O caráter técnico e maquinal desse aparelho de Estado é também o caráter de Andergast, este funcionário modelar do aparelho judicial: sua maneira de lidar com as pessoas é comparada pelo narrador a um engenhoso e eficiente aparelho elétrico, a um dispositivo industrial cujo objetivo é a eficiência na concretização de resultados, no alcance de metas préestabelecidas, perseguidas de maneira obsessiva e implacável: "Era como numa instalação elétrica modelar, um funcionamento confiável de contatos, ligações secretas e interruptores poupadores de tempo.” (WASSERMANN 1928: 15) ${ }^{6}$

A “objetividade” dessa mentalidade tipicamente oitocentista, obcecada por uma eficiência de caráter industrial, torna-se uma espécie de distorção de caráter epidêmico

\footnotetext{
${ }^{6}$ Es war, wie bei einer musterhaften elektrischen Anlage, ein verläßliches Funktionieren von Kontakten, geheimen Leitungen und Zeitsparenden Schaltapparaten.
} 
que, segundo o olhar de Wassermann, atinge todas as esferas da sociedade - da família às grandes instituições responsáveis pela produção, justiça, saúde e assim por diante: “Ações autônomas deveriam ser impedidas tanto quanto possível, mas de que maneira? Era preciso domar o espírito, esse perigoso material explosivo do mundo.” (WASSERMANN 1928: 36) ${ }^{7}$

A substituição da autonomia pela heteronomia, da auto-determinação pela submissão à ordem é, assim, o objetivo da educação e da formação exemplares que Andergast impõe a seu filho - como também a que o Professor Quandt impusera a Kaspar Hauser no romance de mesmo título, publicado pela primeira vez em 1908. Disciplinar, submeter à ordem pré-estabelecida, adaptar ao quadro institucional existente, passa a ser a meta de uma educação que Wassermann representa como opressiva, tolhedora da individualidade, massacrante e, no limite, assassina. Nesse sentido, Andergast torna-se um paradigma de seu tempo, alguém que "é extraordinariamente alemão, isto é, no mais moderno sentido do termo.” (WASSERMANN 1928: 37) ${ }^{8}$

Para Herr von Andergast o serviço era um chamado e a profissão uma missão. Ele era o encarregado de um senhor absoluto, cujos interesses ele representava, em cujo nome ele trabalhava e cujo absolutismo asiático de poder não poderia ser colocado em xeque por meio de acomodações no rigor das formas de governo. (...) Todos os tipos de laços humanos eram secundários ante as obrigações funcionais. O princípio que o sustenta é o da imutabilidade, seu tempo é todo o tempo, a crença religiosa na hierarquia à qual ele pertence faz dele um monge, um asceta e, sob determinadas circunstâncias, um fanático. (WASSERMANN 1928: 39) ${ }^{9}$

Esse absolutismo burocrático tão inflexível quanto incompreensível, e tão rigoroso quanto isento de qualquer "contaminação" humana, é a contrapartida da inocência e da ingenuidade - que em Kaspar Hauser aparece na figura do adolescente misterioso que surge, certa madrugada, em Nürnberg - e que reaparece, com uma força redentora, também em Der Fall Maurizius na pessoa de Etzel - ele também um

\footnotetext{
7 Selbstständige Handlungen mußten so lange wie möglich unterbunden werden, aber wie und mit welchen Mitteln? Es war ja der Geist, der zu zähmen war, der gefährliche Explosivstoff der Welt.

${ }^{8}$ Hierin war er außerordentlich deutsch, will heißen, nach dem modernsten Begriff davon.

${ }^{9}$ Herrn von Andergast war der Dienst Berufung, der Beruf Sendung. Er war der Beauftragte eines absoluten Herrn, dessen Interessen er vertrat, in dessen Namen er wirkte und dessen asiatische Machtvollkommenheiten durch Lockerung der Regierungsformen nicht beeinträchtigt werden konnten. (...) Jede menschliche Bindung war der amtlichen gegenüber von untergeordneter Bedeutung. Unwandelbarkeit ist das Prinzip, das ihn trägt, seine Zeit ist alle Zeit, der religiöse Glaube an die Hierarchie, der er angehört, macht ihn zum Mönch, zum Asketen, unter Umständen zum Fanatiker.
} 
adolescente criado sem a doçura, a compaixão e a proteção maternas. O absolutismo burocrático se afigura, assim, como a face mais sombria de uma tirania racionalista e patriarcal, de resto semelhante à que atormenta tantos dos personagens de Franz Kafka de Josef K., de Der Prozeß, a Gregor Samsa, de Die Verwandlung.

Princípio autônomo e desvinculado de quaisquer outras leis - sejam essas as da natureza, sejam as da religião - esse absolutismo torna-se, em si mesmo, criador, administrador e, sobretudo, implementador das leis, e as leis, em Der Fall Maurizius, são o único parâmetro, ainda que seu vínculo com um ideal de Gerechtigkeit tenha se rompido de maneira irreversível. A rigidez de Andergast lembra a de uma figura de pedra num templo grego e seu próprio filho o vê como tal ${ }^{10}$. Materialização de uma justiça privada de vitalidade e de substância, ele é como um monumento sem vida instalado nos palácios suntuosos erigidos pelo Estado, que funcionam como ícones e representações de um poder absoluto: “Em sua infância, ele (Etzel) imaginava que seu pai ficava sentado no centro do universo, gravando com um formão todos os pecados e todas as transgressões dos moradores da cidade numa placa de mármore.” (WASSERMANN 1928: 42) ${ }^{11}$

\section{Do autoritarismo à desorientação}

Wassermann propõe, em Der Fall Maurizius, um olhar profundamente cético sobre a sociedade alemã de seu tempo. Ainda que o romance tenha dois tempos ficcionais distintos, um no período anterior à Primeira Guerra Mundial e o outro no entre-guerras, as existências de seus personagens são, sem exceção, delimitadas pelo mesmo caráter inflexível e imutável dos parâmetros característicos do racionalismo burguês oitocentista: patrimônio e renda, posição social e reputação, bom gosto e relacionamentos. Essas relações de força e de submissão são os vetores que determinam as trajetórias e os destinos dos personagens, enquanto valores superiores como a Gerechtigkeit, a dignidade, a virtude, a solidariedade humana, característicos das sociedades tradicionais - e ao menos idealmente fundamentos da sociedade ostjüdisch só estão presentes, em seu universo, de forma residual, em estado de degradação, isto é, na forma de aparências e de simulacros que, evidentemente, deixaram de ser objetivos e

\footnotetext{
${ }^{10} \mathrm{cf}$. WASSERMANN, 1928: 35

${ }^{11}$ Als Kind hatte er sich eingebildet, daß der Vater im Mittelpunkt des Weltalls saß und sämtliche Sünden und Vergehungen aller Leute in der Stadt mit einem Marmorgriffel auf eine Marmortafel verzeichnete.
} 
ideais a serem perseguidos em si mesmos para se tornarem imagens falsificadas, signos que parecem legitimados pelo selo da autenticidade, mas que se destinam, não obstante, apenas à aplicação prática no jogo de forças diário de um mercado e de uma política que parecem abarcar tudo.

O estado de corrupção em que se encontra mergulhada a sociedade alemã que Wassermann descreve nesses dois momentos é posto em evidência pelo despertar da consciência de Etzel, que passa a olhar com desconfiança para o temido e orgulhoso promotor, cujos atos de violência estão sempre ocultos sob o manto escuro da legitimidade e da correção, e cujo poder leonino parece abarcar todas as esferas de uma sociedade em que o medo é o cimento que mantém seus membros em seus devidos lugares.

O pragmatismo alemão, assim, apresenta-se como a falsificação daqueles valores que supostamente o legitimariam, e a inocência de um adolescente em que apenas começa a despertar a consciência é o que traz à luz este estado de adulteração. Nesse sentido, também, Der Fall Maurizius repete o enredo de Kaspar Hauser: em ambos os livros, jovens alheios aos mecanismos da ordem social expõem, por meio de seus atos inocentes, a perversidade da ordem vigente e se tornam, por isso mesmo, elementos perigosos, que a põem em xeque e a ameaçam.

Não são casuais, assim, as referências a Kaspar Hauser que o Professor FörsterLöring, pai de amigos de Etzel, faz, ao expor ao jovem a participação de seu pai em sua veemente e injusta acusação, que levou à condenação de Leonhart Maurizius - uma acusação que ele considera memorável e exemplar, enquanto minimiza as vozes dos críticos de Andergast, igualando-o aos tolos que "ainda hoje consideram que o pobre Kaspar Hauser foi um mártir”. (WASSERMANN, 1928: 101). É esta comparação o que mais provoca a desconfiança de Etzel - ele mesmo é alguém que estudou a fundo a história do jovem encontrado em Nürnberg. ${ }^{12}$

A ordem encarnada pelo pai, assim, afigura-se a Etzel como assentada sobre bases falsas, da mesma forma como são falsas as bases da sociedade que condenou o próprio Kaspar Hauser. E o reconhecimento dessa situação impõe a ele a missão de seu desmascaramento. Uma ética da natureza, portanto, uma Gerechtigkeit ancorada em princípios cósmicos como a Diké dos gregos arcaicos, representada por Hauser tanto quanto pelo próprio Etzel, é o que se contrapõe à coerção e às imposições da sociedade,

\footnotetext{
12 cf. WASSERMANN, 1928: 102: er hatte sich mit der Geschichte des Findlings beschäftigt und viel darüber gelesen.
} 
travestidas de justiça, porém, na visão de Wassermann, privadas de qualquer legitimidade.

Os personagens centrais de Der Fall Maurizius - Andergast, Maurizius e sobretudo o judeu Waremme - são, ao mesmo tempo, órfãos e desertores de um conjunto de valores e de ideais arruinados pelo tempo e pelos acontecimentos e pela história. Maurizius, Andergast e Waremme emergem das páginas do romance como homens desorientados e confusos, como perplexos e perdidos, como privados de referenciais seguros, como reflexos e aspectos divergentes do esvaziamento de um mesmo ideal e do esfacelamento de uma mesma constelação - aquela de um Deutschtum fundamentado nas noções de Bildung e de Gerechtigkeit, cujo caráter supostamente auspicioso foi, para os judeus de língua alemã, a grande promessa não concretizada do século 19.

\section{A história de uma desilusão}

A idéia de Gerechtigkeit, isto é, de justiça e de retidão moral, que ocupa o lugar central na constelação retratada nesse romance, é também a idéia cujo desmentido, cujo desrespeito, cujo esquecimento, são apontados por Wassermann como os desencadeantes da situação crítica retratada nos desdobramentos da narrativa. Trata-se de um conceito central que ocupa um lugar fundamental, também, em toda a tradição espiritual judaica, desde a bíblia até a literatura talmúdica, e é o conceito-chave da erudição judaica, pressuposto para qualquer tipo de aprofundamento em seus meandros. Mas é também o conceito central, de cuja observância, por parte dos povos entre os quais viveram, dependiam a vida e a morte dos judeus da Europa. O sonho de integração judaica ao universo cosmopolita europeu da Bildung tinha como princípio fundamental a subjacente, e como pressuposto básico e inalienável, a crença no triunfo da Gerechtigkeit por meio do avanço do Fortschritt e da Bildung - e do desaparecimento, daí decorrente, dos preconceitos e das superstições que mantiveram os judeus numa situação de marginalidade por séculos a fio.

Por meio do romance, Wassermann dá a entender que a disposição dos antepassados de Waremme, judeus provenientes da Polônia prussiana, em deixar para trás o seu próprio legado, de pronto identificado com a superstição, para ingressar naquele universo que, em seu imaginário, estava construído sobre a noção de triunfo 
universal da Gerechtigkeit verdadeira, não teve por contrapartida o triunfo generalizado desse princípio constitutivo sobre a totalidade da sociedade alemã. O resultado de sua disposição, isto é, de seu esforço em se integrarem à sociedade alemã, foi que Waremme, como os milhares de descendentes de judeus em busca de assimilação à cultura alemã, por gerações a fio desde os tempos de Heinrich Heine, cresceu em meio a um vácuo de valores, numa família que, do ponto de vista social e espiritual, pairava no ar entre dois mundos, já não mais pertencendo ao mundo da tradição judaica e ao universo consagrado pelos ancestrais, nem tampouco fazendo parte de um universo cosmopolita centrado na noção de Bildung, cujas promessas nunca chegaram a se concretizar verdadeiramente. Na verdade, a trajetória de Waremme reproduz, nesse sentido, a dos próprios pais de Wassermann, conforme retratada em seus escritos autobiográficos.

Assim, se a falência da Gerechtigkeit é a causa visível da “malaise” generalizada que perpassa esse romance, é também esse mesmo fenômeno que, aplicado ao caso específico dos judeus no universo da cultura germânica, melhor representa a frustração de seu projeto de transformação e de assimilação cultural. É também a idéia de Gerechtigkeit que leva Etzel a revoltar-se contra o mundo de seu pai, conduzindo-o à aventura que o leva aos labirintos de um caso judicial cuja elucidação expõe não só a crise da justiça alemã - e das próprias noções centrais do Estado - mas também uma crise generalizada de valores que se torna, ela mesma, o assunto central do romance, em todos os seus desdobramentos, tanto de caráter universal quanto especificamente judaico.

Evidentemente este tema não é uma exclusividade de Wassermann, nem mesmo dos prosadores alemães de origem judaica de seu tempo. A questão do estranhamento e a crítica ao autoritarismo herdado do absolutismo esclarecido, mas que continuaria vigente no período entre-guerras, é um tema corrente na literatura alemã das décadas de 20 e 30, ao mesmo tempo em que a própria problemática do estranhamento e da alienação são centrais a toda a literatura do século 20 - dentro e fora das fronteiras alemãs. Assim, o caso particular narrado em Der Fall Maurizius, no qual está inscrita, também, toda a problemática da situação dos judeus na Alemanha, universaliza-se e torna-se, como a obra de Kafka, emblema de um Zeitgeist.

A frustrada assimilação de Gregor Waremme à sociedade alemã, assim, pode também ser vista como um retrato da própria incapacidade do homem moderno de chegar a termos com as instituições e os poderes que governam a sua existência. No 
entanto, neste artigo, não gostaria de perder de vista a particularidade e a especificidade dos personagens concebidos por Wassermann, e que, de alguma forma, encontram correspondência em sua própria experiência como Deutscher und Jude.

A adulteração da Gerechtigkeit, o desmascaramento dos responsáveis pela sua má administração, a incapacidade das instituições criadas para executá-la - o retrato que Wassermann propõe da vida na Alemanha de seu tempo já não tem mais como contrapartida ou termo de comparação a vida no antigo gueto ou na aldeia judaica, referências ausentes de seu repertório e de seu horizonte histórico, obliteradas seja pelo desejo de livrar-se de superstições, formulado e levado a cabo ao longo do século 19 pelas gerações que se propuseram a integrar-se na "civilização moderna”, seja pelas idealizações da liberdade proporcionada pela modernidade oitocentista. E a desolação de Waremme está vinculada, também, à perda irreversível dessa perspectiva: no relato que ele faz a Etzel a respeito de sua aventura americana, ele fala, também, de seu encontro com judeus russos e com mestres hassídicos, com a constatação resignada de que perdeu, para sempre, o momento oportuno para absorver os seus ensinamentos, já que, quando os conheceu, sua experiência na Alemanha e posteriormente nos Estados Unidos, um país onde “tudo cheira a sangue” (WASSERMANN 1928: 361) já o tornara irremediavelmente cético.

Bildungsroman às avessas de um mundo cujo principal substrato ético - isto é, a noção de Gerechtigkeit - parece ter se desvanecido de forma irreversível, na esfera judaica tanto quanto na sociedade alemã - Der Fall Maurizius torna-se, assim como o Kaspar Hauser, um Entfremdungsroman, isto é, um “romance do estranhamento", termo que parece adequado para classificar uma parcela significativa da literatura alemã do período entre-guerras. A confrontação com o caráter ilusório dessa Gerechtigkeit acaba por atingir o aparentemente inabalável promotor Andergast. Numa visita ao presídio de Kressa, onde está encarcerado Leonhart Maurizius, ele acaba sendo levado ao questionamento e à perplexidade, mas este despertar de sua consciência apenas é desencadeado depois que seu filho Etzel parte do abrigo e da proteção da casa paterna, incitado pela hipótese da condenação injusta de Maurizius, para descobrir que o mundo inteiro está mergulhado na injustiça e na violência.

Por outro lado, se não existe, para Waremme, a referência positiva da tradição como um universo organizado em torno da um padrão válido de Gerechtigkeit, nem tampouco um modelo confiável desse mesmo conceito nas sociedades modernas em que viveu, seja na Europa, seja nos Estados Unidos, sua atitude existencial resignada, cética 
e algo marcada pela nostalgia por uma tradição espiritual que não chegou a conhecer, o leva a perder inteiramente a fé e a esperança nas promessas - sejam essas da civilização cristã e germânica, das quais ele fora um apóstolo em sua juventude, sejam as da modernidade industrial de molde americano, sejam, ainda, as promessas de um judaísmo que não chegou a ser conhecido.

\section{Em busca das origens}

As pilhas de livros a respeito da tradição judaica que Etzel encontra em na morada suja e precária de Waremme traduzem sua busca tardia por origens ignoradas uma busca que parece fadada, de antemão, ao malogro, porque o malogro tem sido o resultado de tudo o que ele se propõe a fazer, não obstante as suas gigantescas capacidades intelectuais, não obstante a sua força mental, que lhe dá a aparência e a aura de um gigante entre os homens.

Os malogros sucessivos de Waremme, que o levaram do epicentro de um movimento pela renovação do Deutschtum em direção a uma existência às margens da sociedade, como professor particular e redator ocasional, vivendo num cortiço em Wedding, um bairro do proletariado berlinense, são também a expressão sombria da falência dos ideais de integração judaica à sociedade germânica - senão ao próprio universo da Bildung. Mas esse personagem de inteligência tão brilhante, e ao mesmo tempo tão frustrado em suas ambições, é também o retrato sombrio, traçado às vésperas do nazismo, dos resultados de mais de um século de busca por integração social, e a enésima encarnação de um pesadelo recorrente ao longo de todo o século 19. Uma mesma história repetida ad nauseam, sempre com o mesmo desfecho sombrio, torna-se uma ladainha trágica e desesperada, um drama sempre idêntico a si mesmo, a consumir gerações de atores condenados a representar um papel fadado, de antemão, à frustração, seduzidos por simulacros cuja falsidade parecem fazer questão de comprovar com a própria experiência.

De super-homem a pária, o caráter demoníaco de Waremme e sua malograda trajetória têm, igualmente, como pressuposto a inexistência da Gerechtigkeit numa sociedade cujos valores se decompõem, precipitando os seus membros na vertigem da ausência de referências, que é o pano de fundo de um enredo sórdido, marcado por traições, mentiras, descaso de todos os laços familiares e quaisquer outras lealdades a 
instâncias superiores ou transcendentes à esfera dos desejos estritamente individuais. Retrato da dissolução dos fundamentos éticos e metafísicos da sociedade alemã tanto quanto daqueles judeus já desvinculados de suas tradições, e também do triunfo do demoníaco sobre o humano, isto é, da destruição, nos indivíduos, daqueles parâmetros e princípios que são o fundamento de uma existência que supere a condição de bestialidade, Der Fall Maurizius retoma um tema ubíquo nas artes e na literatura alemã das décadas de 20 e 30 - do cinema de Fritz Lang à pintura de Georg Grosz; de Berlin Alexanderplatz ao teatro de Brecht; de Kurt Weil a Die Schlafwandler, de Hermann Broch $^{13}$.

Evidentemente, a crise de valores que contamina nesse romance de Wassermann a sociedade alemã de uma extremidade a outra, encontra barreiras de resistência que só aos poucos vão sendo derrubadas. O moralismo rígido e desumanizado de Wolf von Andergast, representante de um conservadorismo ancorado numa tradição ossificada e fossilizada, e cuja substância foi desgastada pela alienação gradativa da realidade e pela fixação a padrões repetitivos e inflexíveis, que não levam em conta qualquer realidade exterior, isto é, esse conjunto de valores encerrado sobre si mesmo, que corresponde, cada vez menos, a uma realidade social, e a uma praxis e a um consenso políticos, é a principal linha de resistência ao desmantelamento ético e espiritual de que trata o romance. Mas a solidez de caráter de Andergast tarda demais a despertar da letargia formalista e burocrática em que se encontra submersa, e demora tanto para divisar o que se passa para além das muralhas intransponíveis que rodeiam os jardins secretos em que se desdobra que, quando isso ocorre, já é tarde demais: sua família, assim como a sociedade em que vive, dissolveram-se, de forma irreversível, num vazio de valores e num formalismo sem substância.

A dissolução de caráter, nos personagens, é também o prelúdio à corrosão generalizada de um tecido social privado de seu substrato ético, do desaparecimento do sentido de dignidade e de orgulho de uma tradição. O caráter farsesco de uma vida social cujas relações estão viciadas pela ausência de fundamento e, de outro lado, de relações familiares que não são capazes de implementar, na realidade, um conjunto de valores aprisionados por uma rigidez castradora é o que promove a sucessão inauspiciosa de acontecimentos retratada aqui: mais do que um crítico de seu tempo,

\footnotetext{
${ }^{13}$ Traduzido para o português sob o título de Os Sonâmbulos, Lisboa, Editora 70, 1988
} 
Wassermann é também uma espécie de profeta que pressente a inevitabilidade da catástrofe política que se aproxima da Alemanha.

\section{6. $O$ paradigma ausente}

Se o entorpecimento ético parece ser a doença do enrijecido Andergast, e se a crise da Gerechtigkeit é a principal linha de força desse romance, nela encontra-se inscrito um outro núcleo de sentido, que é o da busca dos judeus por um lugar na modernidade - e o custo de semelhante busca. A perversidade absoluta é encarnada, em Der Fall Maurizius, por Waremme, esse filho de Ostjuden já desvinculados de seu legado ético, que parece, à maneira de Fausto, compactuar com as forças demoníacas e acaba vitimado por elas. Waremme pretende, na primeira parte do romance, dar um passo a mais no caminho percorrido pelos judeus germanizados a partir de suas aldeias no Leste e de seus guetos em direção ao universo da Bildung alemã e européia. Se esse ideal oitocentista de Bildung catalisou a vida espiritual de gerações de judeus em busca de assimilação à cultura alemã, o desenvolvimento de uma nova ideologia cultural de viés nacionalista, na Alemanha, a partir do final do século 19, e o concomitante crescimento do anti-semitismo, aos poucos foram minando esta nova fé judaica na Bildung, que fora anunciada em termos tão grandiloqüentes pelas primeiras gerações da Haskalá ou Iluminismo judaico.

Constatando, com resignação, o limitado sucesso da assimilação judaica à sociedade alemã depois de mais de um século de “emancipação”, e escrevendo em 1927, no mesmo ano em que Jakob Wassermann compunha seu Der Fall Maurizius, o rabino liberal Benno Jacob afirmou que “os judeus alemães assimilaram os valores culturais da Alemanha, mas não foram assimilados à sociedade alemã”. (MENDESFLOHR, 1999: 3). ${ }^{14}$

Paul Mendes-Flohr discute o surgimento, no fim do século 19, de dois modelos concorrentes de identidade coletiva na Alemanha: de um lado, um modelo individualista, organizado em torno dos valores de uma Bildung que tem por pressuposto o cultivo interminável do indivíduo, e a exploração incessante de aspectos sempre novos do conhecimento e da experiência estética, isto é, um modelo baseado na

\footnotetext{
${ }^{14}$ German Jews, however, were painfully aware, as the liberal rabbi Benno Jacob put it in 1927, that they were but "assimilated in the accusative" - that is, they assimilated the cultural values of Germany - and not "assimilated in the dative", that is they were not assimilated into German society
} 
noção grega de Paidéia, cuja ênfase estava no cultivo da interioridade, numa concepção de cultura como uma atividade primordialmente espiritual, que tinha em vista um aperfeiçoamento constante das características humanas. De outro lado, surgia o modelo de identidade coletiva baseado na noção de Volk, ou povo, conforme o modelo criado por Nietzsche, que recomendou, expressamente, a substituição da Bildung, com sua ênfase cosmopolita, por uma Bildung genuinamente alemã - uma idéia cultural e pedagógica fundamentada naquilo que ele e Richard Wagner denominaram “o renascimento do mito germânico", isto é, um retorno às origens medievais de uma identidade especificamente germânica, que re-atualizasse seus valores míticos.

Tendo ingressado no caminho da modernidade, os judeus, na Alemanha, sempre foram fiéis à concepção cosmopolita de Bildung, inclusive supondo que a participação nesse universo lhes facultaria a plena aceitação por parte da sociedade alemã. Mas na medida em que triunfava, século 20 adentro, um ideal völkisch de cultura, cada vez mais os judeus viram-se isolados em sua paixão anacrônica pela Bildung cosmopolita - e efetivamente, segundo Mendes-Flohr, “os judeus foram os últimos guardiães da verdadeira Bildung alemã” (MENDES-FLOHR 1999: 12) ${ }^{15}$.

Sua devoção às expressões mais refinadas da cultura alemã - arte, literatura e música - foi, porém, ao final indicativa da ligação singularmente apaixonada da ética da Bildung, o ideal humanista, nascido do iluminismo germânico, cultivo das capacidades morais e intelectuais de cada um por meio do estudo da literatura e da filosofia, e do refinamento das sensibilidades estéticas por meio das artes e da música, por parte dos judeus alemães. (MENDES-FLOHR, 1999: 26). ${ }^{16}$

Se a Bildung proporcionava respeitabilidade aos antigos residentes do gueto - ao menos em seus próprios olhos - e tornou-se, nas palavras de Berthold AUERBACH, a fonte de uma nova religião - a religião da Kultur, da qual se tornaram devotos todos os estratos do judaísmo alemão - com o desencadeamento do movimento em prol de uma cultura völkisch alemã, capitaneado pelos ideais de Nietzsche e Wagner, que se tornava

\footnotetext{
${ }^{15}$ Indeed, the Jews were "the last guardians of the original German idea of Bildung." Yet this focus tends to blur the fact, emphasized in this volume, that upon entering the Bildungsbürgertum, Jews laid claim not only to German Kultur and thus identity but also to the right to maintain their Jewish identity.

16 cf. Mendes-Flohr, Paul. German Jews - A Dual Identity. New Haven, Yale University Press, 1999, p. 26: Their devotion to the most refined expressions of German culture - art, literature and music - was, however, at bottom indicative of German Jewry's uniquely passionate embrace of the ethic of Bildung, the humanistic ideal, born of the German Enlightenment, of self-cultivation of one's intellectual and moral faculties through a study of literature and philosophy, and the refinement of one's aesthetic sensibilities through the arts and music.
} 
cada vez mais importante e popular, e em que o nacionalismo, com seu culto aos mitos e símbolos germânicos, se afastava dos ideais iluministas, os que permanecerem apegados a uma visão cosmopolita da humanidade, conforme os ideais da razão e da Bildung, tornaram-se a cada tanto mais anacrônicos e mais estranhos às tendências que se tornariam dominantes na sociedade, preparando o território, inclusive, para a ascensão do nacional-socialismo.

Waremme é retratado por Wassermann - no que pode ser considerado uma alusão autobiográfica - como alguém que, desde a infância, foi educado para ingressar no universo da Bildung. Conversando com Etzel von Andergast, ele afirma:

Aqueles que nasceram por volta de 1880 estavam numa situação incômoda em sua juventude. Em casa e na escola recebia-se tudo o que era necessário para a vida burguesa e para a assim chamada vida elevada: os princípios e os ideais, o rendimento mensal - quem não o tivesse já desde o início não contava - e a Bildung. Mas tudo era esburacado e esgarçado. Só o rendimento era algo sólido. O restante era ouro falso e imitação barata, dos presentes de Natal e de casamento até o entusiasmo pela Antigüidade e pelo Renascimento, dos costumes das fraternidades de estudantes até as celebrações patrióticas e o "trono e o altar". (WASSERMANN, 1928: 207). ${ }^{17}$

Ao alcançar a vida adulta, cético com relação à sua formação tanto quanto com relação ao sucesso obtido pelos devotos da Bildung em seu projeto de integração à sociedade alemã, ele dá um passo inesperado e pirotécnico ao tornar-se um ideólogo do pan-germanismo, que rompe totalmente com suas origens judaicas e se coloca no epicentro de um movimento nacionalista embriagado pelos ideais da cultura völkisch: um movimento que propõe a restauração da Alemanha por meio da ressurreição de seus mitos e de suas tradições medievais, e sua soberania sobre toda a Europa. Íntimo da elite política e econômica, ele aproveita-se de sua aparência pouco semita para ignorar suas raízes, e passa a apregoar idéias que ecoam, evidentemente, as dos idealizadores do renascimento da cultura völkisch:

O senhor pode imaginar que um homem minta a si mesmo a respeito de seu nascimento? É uma coisa complicada. Não querer ser o que se é, negar raízes da qual

\footnotetext{
17 Die um achtzehnhundertachtzig Geborenen waren als junge Menschen in einer üblen Lage. Vom Haus und von der Schule bekam man alles mit, was man für das bürgerliche und für das sogenannte höhere Leben brauchte, die Grundsätze und die Ideale, die Monatsrente, wer die nicht hatte, zählte erst gar nicht mit, und die Bildung. Aber es war alles löcherig und fadenscheinig, nur die Rente, die war was Festes, das übrige war Talmi und billige Imitation, von den Weihnachts- und Hochzeitsgeschenken bis zur Begeisterung für Antike und Renaissance, vom studentischen Komment und den patriotischen Feiern bis zu ,Thron und Altar'.
} 
se nasceu significa portar a própria pele como se fosse um casaco emprestado. Eu fui o filho de pais judeus que viviam na segunda geração das liberdades civis. Meu pai ainda não havia se dado conta que a situação de aparente igualdade de direitos na realidade era apenas tolerância. Gente como o meu pai, de resto um homem excelente, pairavam no ar, religiosa e socialmente. Já não tinham mais a antiga fé, e negavam-se, em parte por bons e em parte por maus motivos, a aceitar uma nova fé, isto é, a fé cristã. O judeu quer permanecer judeu. O que é isso: judeu? Não há ninguém no mundo capaz de responder a esta questão de maneira satisfatória. Meu pai orgulhava-se da emancipação, uma invenção astuciosa, essa emancipação, por meio da qual o oprimido perde a prerrogativa de poder se queixar. A sociedade o exclui, o Estado o exclui, o gueto físico tornou-se um gueto espiritual, a gente se golpeia no peito e chama isto de emancipação. (WASSERMANN 1928: 329). ${ }^{18}$

Evidentemente Waremme não é mais um Ostjude, seja no sentido religioso, seja no sentido puramente étnico, já que se caracteriza por uma adaptação, desde cedo, aos parâmetros e aos ideais da Kultur alemã e cosmopolita - aos quais, posteriormente, dá as costas. Ele conhece à perfeição as principais línguas do ocidente “civilizado” e sentese inteiramente à vontade no universo da literatura e das artes alemãs. Ao tornar-se líder de um movimento pan-germanista, porém, que exorta a Alemanha, aliada à Igreja Católica, a assumir um papel hegemônico na Europa, pretende dar um passo além no projeto de integração cultural proposto pelo Iluminismo. Por sua própria origem, num lar aculturado, ele é alguém que poderia ter percorrido em sua integridade o iter que partia do gueto em direção à Europa. Porém chegar ao extremo de uma assimilação aos ideais völkisch da cultura alemã - e não apenas aos ideais da Bildung abraçados pelos judeus germanizados em bloco - faz dele uma caricatura, um assimilacionista levado ao paroxismo. E o resultado de seu empenho é, outra vez, como o fora para seus pais, o de ficar pairando entre dois mundos, o que, desde os tempos de Heine, não constitui propriamente uma novidade.

Tradução do malogro de um sonho de germanização dos judeus alemães levado a seu zênite, Waremme acaba, como tantos outros que se deixam levar pelos sonhos impossíveis de suas juventudes, vivendo à margem da sociedade. Ele “dá aulas de

\footnotetext{
${ }^{18}$ „Können Sie sich vorstellen, daß ein Mensch sich selber über seine Geburt belügt? Komplizierte Sache. Der nicht sein wollen, der man ist, die Wurzel verleugnen, aus der man gewachsen ist, das heißt die eigene Haut wie einen geborgten Mantel tragen. Ich war das Kind jüdischer Eltern, die in der zweiten Generation bürgerlicher Freiheit lebten. Mein Vater war noch gar nicht zum Bewußtsein gekommen, daß der Zustand scheinbarer Gleichberechtigung im Grunde nur Duldung war. Leute wie mein Vater, ein ausgezeichneter Mann sonst, hingen religiös und sozial in der Luft. Den alten Glauben hatten sie nicht mehr, einen neuen, will heißen den christlichen, anzunehmen weigerten sie sich, teils mit guten, teils mit schlechten Gründen. Der Jude will Jude sein. Was ist das: Jude? Volkommen befriedigend kann es kein Mensch erklären. Mein Vater war stolz auf die Emanzipation, eine listige Erfindung das, sie nimmt dem Unterdrückten den Vorwand, sich zu beklagen. Die Gesellschaft schließt ihn aus, der Staat schließt ihn aus, das körperliche Ghetto ist zu einem seelischen und geistigen geworden, man wirft sich in die Brust und nennt es Emanzipation.
} 
inglês, francês, espanhol, italiano, português, redige necrológios, matérias pagas em jornais, anúncios comerciais e coisas assim.” (WASSERMANN 1928: 109). ${ }^{19}$ e faz suas refeições na pensão de Frau Bobinski, freqüentada pelo demi-monde berlinense, um verdadeiro bestiário urbano que reúne exemplos de todas as espécies de uma fauna de ociosos e pretensiosos, que mal são capazes de sobreviver, característica da capital alemã nos anos 20: aí encontram-se cantores e pianistas fracassados, solteirões encanecidos e desencaminhados, barmen desempregados e vendedores sem ocupação, homossexuais, cocainômanos e jogadores compulsivos - enfim, um ambiente que reflete, em tudo, uma sociedade desorientada e confusa, que faz pensar nas figuras perturbadoras sempre presentes nas obras de arte do expressionismo alemão:

Pessoas de natureza dúbia, descarrilados e vagabundos de todos os tipos, nadadores exaustos pela grande correnteza. Gente de elegância apodrecida e de pobreza mal disfarçada, vendedores desempregados, virtuoses viajantes, pequenos atores de subúrbio sem contrato, agentes que se encontravam às vésperas de golpes ousados, ou depois de golpes malogrados, barmen e dançarinas das casas de entretenimento da região, alguns provincianos que tinham vindo para a cidade com as suas últimas esperanças e agora estavam ali, como navios encalhados em bancos de areia, um ou outro indivíduo politicamente suspeito, uma esposa que fugira do lar, uma jovem, filha de pastores do Leste, que queria entrar para o mundo do cinema. (WASSERMANN 1928: 240). ${ }^{20}$

Este ambiente desolador, característico da decadência urbana, das esperanças frustradas e das promessas não-cumpridas, esse grande atoleiro dos sonhos abortados, é também o lugar ao qual se destina esse Waremme, o descendente de Ostjuden que sonhara com os mitos grandiloqüentes de uma cultura völkisch germânica da qual os judeus estiveram, por definição e desde o princípio, excluídos. Assim como os demais freqüentadores da pensão de Frau Bobinski, ele parece pertencer integralmente a um universo urbano de desenraizados e frustrados, vítima da desmedida de suas próprias ambições, privados de referências claras, e sobretudo presas fáceis de ilusões urbanas cujo caráter devorador parece revelar-se apenas quando já é tarde demais.

19 Unterrichtet englisch, französisch, spanisch, italienisch, portugiesisch, verfaßt Nekrologe, Eingesandtes an Zeitungen, Geschäftlsreklamen und so.

20 Personen von zweifelhafter Beschaffenheit, allerlei Entgleiste und Strauchelnde, mattgewordene Schwimmer auf dem großen Strom, Leute von angefaulter Eleganz und schlechtverdeckter Armut, stellenlose Kommis, reisende Virtuosen, kleine Vorstadt-Schauspieler und Schauspielerinnen ohne Engagement, Agenten, die vor einem gewagten oder nach einem mißlungenen Coup waren, Barmixer und Eintänzer aus den Vergügunsstätten der Umgegend, ein paar Provinzler, die mit ihren letzten Hoffnungen in die Hauptstadt gekommen waren und nud festsaßen wie ein Wrack auf einer Sandbank, ein oder das andere politisch verdächtige Individuum, eine Ehefrau, die aus dem gemeinsamen Haushalt geflüchtet war, ein junges Mädchen, Pfarrerstochter aus dem Osten, das zum Kino wollte. 
Se Waremme revela um interesse tardio pelas próprias origens étnicas e culturais, expresso por meio dos livros que se encontram em sua inóspita habitação (WASSERMANN 1928: 235), não existe nada que possa ser considerado judaico em seu estilo de vida. Waremme é alguém que não gostava dos judeus, e sim da cultura e da civilização alemãs ${ }^{21}$, e que via como suas a língua e a cultura, os heróis e as canções, as paisagens e as cidades da Alemanha, que "amava de maneira mais profunda do que eles (os alemães), e compreendia melhor do que eles” (WASSERMANN 1928: 330). ${ }^{22}$. O tema do judeu desenraizado que busca ancorar-se na solidez da tradição germânica - quase um lugar comum na literatura judaica alemã - repete-se aqui, sem grandes surpresas ou variações, apesar do grau extremo a que Waremme leva esse esforço.

Figura característica de uma era de liberdade e de autonomia humana, ele encarna aquela ambição, que é talvez a característica determinante do horizonte cultural daquelas gerações de egressos do gueto que se voltam para as próprias origens com antipatia, e que, em contrapartida, fascinam-se com todas as culturas da Europa - e vê a si mesmo como a quintessência de um espírito europeu, tributário de todos os "gênios" da cultura laica do continente - de Petrarca a Goethe e de Fídias a Giotto, de Ovídio a Nietzsche e de Péricles a Nostradamus. ${ }^{23}$

\section{Entre dois mundos}

A ambição ilimitada de uma Bildung que se propõe a abarcar todos os séculos e todos os meios expressivos da cultura de um continente, assim, faz dele um estereótipo tardio das próprias ambições do humanismo europeu, e também um retrato fiel do caráter ilusório das ambições ilimitadas desse humanismo: ao alcançar a maturidade, o malogrado Waremme é um homem cujo espírito está exaurido pelos seus anos de participação num sonho coletivo inatingível, e cujo horizonte existencial, numa cruel forma de Nêmesis, parece ficar restrito à busca por satisfação de suas necessidades mais básicas.

Nem judeu nem alemão, desvinculado de quaisquer princípios transcendentes ou sociais, Waremme torna-se a enésima encarnação de um dilema caracteristicamente

\footnotetext{
${ }^{21}$ cf. WASSERMANN 1928: 330 e ss.

22 "Ich liebte das alles tiefer als sie selber es lieben und verstand es besser als sie."

${ }^{23}$ cf. WASSERMANN 1928: 355
} 
moderno, com o qual o próprio Wassermann se defrontou a vida inteira. Seu destino patético é decorrência direta das aporias próprias a esse dilema: devorado pelos enigmas que não é capaz de decifrar, ele aparece, confinado à pobreza e à desilusão, como mais uma vítima de uma esfinge insaciável, cujos desafios, não obstante, continuam a capturar as idéias e as paixões daqueles que cruzam o seu caminho.

A história do judaísmo alemão é também a longa história de um amor nãocorrespondido, e Waremme torna-se um símbolo não apenas da falência do ideal judaico de aculturação e de modernização, isto é, de integração a um universo europeu de molde cosmopolita, como do próprio ideal grandiloqüente de uma Bildung universal. Waremme, assim, representa uma volta a mais no parafuso da construção da imagem daquele judeu que, desvinculado da tradição e incapaz de integrar-se a um sistema de valores que, em si mesmo, se encontra em decomposição, paira sobre o vazio - uma condição propícia à geração e ao florescimento de monstruosidades.

Não é por acaso que esse filho de Ostjuden desenraizados aparece, na narrativa, como o autor de uma tradução do Górgias, de Platão - um diálogo da filosofia moral entre Sócrates e o retórico asiático Górgias, em que se discute a existência de uma justiça transcendente e absoluta - ponto de vista defendido por Sócrates, com o qual seu interlocutor discorda, alegando que a justiça é uma mera questão de persuasão. O substrato desse diálogo, no entanto, parece escapar ao próprio tradutor: Waremme é, à sua maneira, uma encarnação moderna do próprio Górgias, que faz triunfar a retórica sobre a justiça, com base na idéia de que a verdade e a mentira são apenas questões de persuasão, e de que não existe nenhum princípio ético real subjacente à condição humana. Ao tornar-se o portador da mensagem de Górgias, para quem a justiça nada mais é do que a manipulação bem sucedida de idéias por meio de discursos capazes de persuadir os ouvintes, e de manipular suas opiniões, Waremme aparece como uma criatura monstruosa e como um prenúncio sinistro dos rumos da história alemã na década de 1930.

O caráter aberrante de Waremme, assim, aparece não como uma invenção própria, mas como a reatualização de figuras e de formas de pensamento já presentes na tradição helênica e, igualmente, na tradição judaica: a figura do “apikoires”, quase folclórica na literatura talmúdica, e que está associada aos seguidores da filosofia epicurista, que tem em sua base a negação dos princípios transcendentes e no sensualismo, aproxima-se do modelo filosófico implicitamente adotado por Waremme. 
Não parece haver nada de novo, portanto, na figura desse personagem: levando ao paroxismo sua condição de deraciné, ele se torna um agente difusor de idéias supostamente modernas que, no entanto, estão na raiz de discussões filosóficas de Sócrates, de Platão, e do Talmude. Waremme, assim, aparece, tanto quanto Górgias, como o avesso de uma idéia de civilização que via na barbárie e na tirania asiática seu contraponto e seu oposto.

\section{Referências bibliográficas}

AschHeim, Steven. Brothers and Strangers: The East European Jew in German and German Jewish Consciousness, 1800-1923. Madison, The University of Wisconsin Press, 1982

ElOesser, Arthur. Vom Ghetto nach Europa. Berlim, Jüdische Buch Vereinigung, 1936

JASPER, Willi. Deutsch - Jüdischer Parnass - Literaturgeschichte eines Mythos. Berlim, Propyläen Verlag, 2004

Mendes-Flohr, Paul. German Jews - A Dual Identity. New Haven, Yale University Press, 1999

Wassermann, Jakob. Der Fall Maurizius. Berlim, G. Fischer Verlag, 1928

Wassermann, Jakob . Mein Weg als Deutscher und Jude. Munique, DTV, 1994

WASSERMAnN, Jakob . Deutscher und Jude. Heidelberg, Lambert \& Schneider, 1984,

WASSERmann, Jakob . Caspar Hauser. Amsterdã, Querido Verlag, 1939

WerTHEIMER, Jack. Unwelcome Strangers. Nova York, Oxford University Press, 1987

WolfF, Larry. Inventing Eastern Europe - The map of civilization on the Mind of the Enlightenment. Stanford, Stanford University Press, 1994 